\title{
Does Safety Training Reduce Work Injury in the United States?
}

\author{
Geetha M. Waehrer ${ }^{\S}$ and Ted R. Miller ${ }^{*}$,
}

Pacific Institute for Research and Evaluation, 11720 Beltsville Drive, Suite 900, Calverton, MD 20705-3111, USA

\begin{abstract}
Using a cross-sectional model, this paper analyzes the relationships between occupational injury rates and worker safety training, workplace safety practices, and health-oriented employee benefits in the United States. We merged U.S. Bureau of Labor Statistics establishment-level data on employee training, benefits, and rates of occupational injuries and illnesses with days away from work, obtaining a data set on 2,358 establishments, $62 \%$ of them with at least 250 employees. Weighted two-stage regression models were used to provide a rare look at the effect of training, benefit packages, and workplace practices on occupational injury rates. The results suggest that safety training increases the reporting of injuries and illnesses but also has real safety effects on days-away-from-work incidents, especially in smaller firms. While overexertion incidents were resistant to safety training, toxic exposure events were reduced in manufacturing establishments with a formal safety training program. Wellness programs and Employee Assistance Programs were associated with lower days-away-from-work injury and illness rates and costs in large firms where they are more common. Workplace innovations like total quality management significantly increased the reporting of days-away-fromwork injuries and illnesses.
\end{abstract}

Keywords: Safety training, occupational injury, evaluation, EAP, wellness program.

\section{INTRODUCTION}

Occupational injuries affect workers, employers and society at large through their impact on medical costs, workplace productivity and pain and suffering associated with injuries. For employers, workplace injuries create disruptions in the work cycle, and in some cases, may call for hiring replacement workers. To achieve productivity goals with a minimum of injuries, employers frequently train workers in the proper and safe use of equipment, invest in ergonomic equipment, and experiment with a variety of work practices designed to reduce injuries. In this paper, we examine the effects of formal safety training programs on workplace injury, focusing on the costliest injuries with days away from work.

The U.S. Occupational Safety and Health Administration (OSHA) strongly promotes safety and health training as an essential component of employers' efforts to provide a safe workplace. Hundreds of requirements for safety and health training are found in occupational safety and health standards promulgated by OSHA [1]. OSHA also limits certain jobs to persons receiving specialized training. In addition to OSHA requirements, firms receive worker's compensation premium discounts for their efforts in injury prevention including safety initiatives.

Safety training can be given via a highly structured formal training program or through more informal ways of

\footnotetext{
*Address correspondence to this author at the Pacific Institute for Research and Evaluation, 11720 Beltsville Drive, Suite 900, Calverton, MD 207053111, USA; Tel: (301) 755-2714; Fax: (301) 755-2799;

E-mail: miller@pire.org

${ }^{\S}$ Dr. Waehrer is a Research Scientist and Dr. Miller a Program Director at the Pacific Institute for Research and Evaluation.
}

providing workers with job-related skills. A survey by the U.S. Bureau of Labor Statistics (BLS) indicates that U.S. employers spend a considerable amount of time and resources on both formal and informal training including safety training. For example, a national survey found establishments with 50 or more employees paid $\$ 7.7$ billion to in-house training staff and $\$ 5.5$ billion to outside trainers in 1994, \$139 and \$98 per employee respectively [2]. Workers spend roughly $4 \%$ of their work hours in some kind of training resulting in additional wage costs. Safety and health training accounts for a quarter of the total hours spent in formal training.

\subsection{Background and Related Literature}

OSHA training requirements are specific to different hazards and therefore vary widely in their instructions about content, frequency and duration, documentation of training, trainer qualifications, and training methods. The most explicit training requirements are found in the Hazardous Waste Operations and Emergency Response standards and the OSHA adoption of the Environmental Protection Agency asbestos abatement work rule [1]. In most workplaces, occupational safety and health (OSH) training is likely to be a natural part of job skills training. In occupations such as logging, for example, "poor technique" is widely reported as a cause of injury resulting from inadequate training and a failure to learn the proper work methods.

The bulk of training activities involve fundamentals programs that instruct workers to avoid known hazards through the proper use and maintenance of equipment and materials. However, training can also be proactive, teaching workers to recognize and head off potential problems through teamwork, via union or management efforts, and 
encouraging workers and supervisors to be jointly accountable for injury control.

A Federal literature review on safety and health training interventions to reduce work-related injury and disease found that most safety training interventions were undertaken in response to site-specific hazards and involved small nonrandom samples of workers [1]. While most training interventions studied did not address OSHA training requirements per se, the review provided support for training as an important part of a firm's hazard control activities.

The extent to which safety training can be transferred to actual jobsite demands, and the employer's commitment to promote training as well as improve post-training productivity and injury outcomes can affect the success of training efforts. These factors can also complicate attempts to evaluate the effects of safety training separately from other workplace factors. Training effects may be easier to detect in more immediate indicators of an establishment's injury record like changes in toxic exposure levels or increased compliance with safe work practices than in effects on ultimate measures of workplace injury. Thus, most studies examine outcomes like worker knowledge and safe behavior rather than direct measures of injury.

A meta-analysis on literature published in English between 1971 and 2003 [3] identified 23 studies with quasiexperimental designs that evaluated the effects of worker safety and health training on OSH outcomes. All but two of the studies found significant positive effects.

Almost none of these studies account for whether firms that provide safety training are more safety conscious to begin with. The provision of safety training is not likely to be randomly distributed among firms. For example, "good actors" may provide safety training but also may have other establishment-wide policies in place that reduce injury rates. Such a scenario would lead to a biased estimate of training effects.

This paper measures the effect of formal occupational safety and health training on days-away-from-work injuries using matched establishment data from two BLS surveys, one on occupational injuries and the other on employer provided training. The latter survey is rich in detail about both training and establishment practices like workplace innovations and employee benefits that could affect injury rates and may also be associated with a greater concern for health and safety. Thus, we expect that our data will help to control for the establishment's safety climate, resulting in cleaner estimates of the effects of safety training and related practices. Regrettably, these unique data were collected in 1993 so our estimates may deviate from more recent program effects.

Besides analyzing injury rates, we examine whether safety training reduces the per worker average cost of daysaway-from-work injuries. We analyze the distribution of days away from work to check whether safety training has a differential effect on injuries of varying severity. We also examine the event underlying the injury (e.g. falls, exertion) to determine if safety training is more effective in preventing certain types of injuries. We expect events such as exposures to toxic hazards that are specifically targeted by OSHA training requirements to be responsive to safety training.

\section{METHODOLOGY}

We examined the effects of safety training on injury outcomes using a unique dataset created by merging matched BLS data on training and injury at the establishment level. For training information, we used the 1993 BLS Survey on Employer-Provided Training (SEPT93) which gathered information on the existence of formal training programs provided or financed by a sample of private non-agricultural establishments [4]. Surveys were mailed to approximately 12,000 establishments and viable data were received from 7,895 establishments, a response rate of $71 \%$. The SEPT93 questioned establishments about the provision of workplace orientation, safety and health training, formal apprenticeship programs, basic skills training including language skills, and job skills training.

In addition to formal training data, the SEPT93 questioned establishments about their use of flexible workplace practices like worker teams, total quality management, quality circles, job rotations, and just-in-time inventories. Establishments were also asked about the provision of employee benefits including health insurance, employee assistance programs (EAPs), and wellness programs. The data includes information on the number of employees: (1) on payroll in 1993, (2) covered by a collective bargaining agreement, (3) who had worked less than a year, or (4) were working part-time. This allowed us to calculate the percentage of new workers, the percentage of part-time workers and the percentage unionized. While our main focus is on training effects, these other establishment characteristics are also likely to affect the workplace injury record.

We merged the training data by establishment with summary data on the injury and illness records of establishments using the contemporaneous 1993 Annual Survey of Occupational Injuries and Illnesses (SOII) [5] collected by the BLS. The SOII collects occupational injury and illness data from logs that employers maintain according to OSHA guidelines. In 1993, employer reports of worker injuries were collected from about 250,000 private industry establishments. The establishments reported the numbers of injuries and illnesses with days away from work, the total annual hours worked by all employees, the annual average number of employees and the establishment's industry. (Henceforth, this paper refers to injury and illness cases as "injuries").

Starting in 1992, BLS supplemented the summary reports of injuries with microdata on cases with days away from work. Approximately 475,000 of the 1993 cases were used to estimate the mean days away from work and associated costs including wage, medical, and pain and suffering costs [6]. Using the costed microdata, we calculated a weighted average total cost by establishment and merged it onto the summary data. The weighted frequency of different injury events (e.g., contact, overexertion) and the number of cases in five duration categories (1-3 days away from work, 4-6, 7$20,21-60,>60)$ were calculated from the microdata and merged with the summary data.

Matching the SOII to the SEPT93 resulted in a final sample of 2,358 establishments with merged data on training and human resource practices combined with injury count, 
cost, event, and severity data. The matched sample has a larger proportion of large firms than the original surveys since large firms were sampled in both surveys with higher probability than smaller firms were. Establishment weights were calculated for the matched data based on the initial SEPT93 weights ${ }^{1}$.

Table 1 shows that our merged data with rescaled weights has a somewhat higher provision of safety training (39\%) than the original weighted SEPT93 survey $(32 \%)$. Of the five other types of formal training surveyed formal job skills training was most prevalent with $62 \%$ of establishments offering training in managerial, technical, sales, computer, cleaning, or production-related skills. This was followed by workplace training (48\%), formal orientation programs $(42 \%)$, formal apprenticeships $(24 \%)$, and basic skills training (2\%).

The provision of formal safety training varies across industries and establishments of different sizes ${ }^{2}$. Safety training is barely offered among establishments in the finance, insurance and real estate sectors, but is much more prevalent in mining, construction, manufacturing, and transportation and utilities industries ${ }^{3}$. This pattern is not surprising since jobs in these industries tend to be riskier and require more attention to safety.

The larger the establishment, the more likely it was to offer training - only $35 \%$ of establishments with fewer than 50 employees provide safety training compared with $91 \%$ of the largest establishments with more than 1000 employees. Larger firms may have a greater incentive to provide safety training to prevent occupational injuries because of the experience rating system. Under this system, large firms' premiums track their own injury records more closely than in small firms where premiums depend more on the average injury experience of their industry.

Establishments providing safety training had a higher proportion of employees covered by union contracts, and fewer part-time or new workers. Establishments with a high level of union involvement may be more sensitive to safety and training considerations. New and inexperienced workers, especially those with under a year of service, have higher injury rates and may require more attention to safety training. However, the incentive to provide general safety training will also be lower for workers with looser ties to the establishment.

Consistent with Gittleman et al. [7], flexible workplace practices and formal training practices tended to go together. Flexible workplace strategies like worker teams, and total quality management were more common in firms with a formal safety training program than without, as were production practices like just-in-time inventory controls.

\footnotetext{
${ }^{1}$ Weighted frequencies in 40 industry-firm-size cells from the matched data were scaled up to match the corresponding frequencies in the original SEPT93 data.

${ }^{2}$ The agricultural establishments in Table $\mathbf{1}$ are in the agricultural services sector, primarily landscaping.

${ }^{3}$ Over half of mining establishments offer formal safety training in our merged data, a similar percentage as in the original SEPT93. However, we expected a much higher percentage in the mining industry which is subject to some of the more stringent safety and health regulations in the workplace. Possibly training is offered in informal, on-the-job ways not captured by our variable or by the union rather than the employer.
}

Establishments with workplace innovations that require more decision-making from individual workers may find it in their interests to provide these workers with all the tools needed to perform well. Many safety training programs encourage workers to reduce hazards through education of co-workers and supervisors, an approach consistent with the "total quality management" philosophy where workers and supervisors are jointly responsible for addressing safety needs.

Establishments with safety training provided benefits like health care, EAPs, and wellness programs at a higher rate than those without safety training. This is not surprising given the correlation between benefits and firm size. In addition, benefits like EAPs and wellness programs may be seen as part of a disability management strategy that seeks not only to prevent injuries but also to minimize the disruptions arising from injuries [8].

Table 1 shows that days-away-from-work cases were a bigger problem for establishments with safety training than without. The rate of days-away-from-work injuries in the matched sample was 1.2 per 100 full-time equivalents (FTEs) for establishments without a formal safety program versus 2.1 cases per 100 FTEs for establishments with one ${ }^{4}$. Days-away-from-work cases also appear more severe in establishments with safety training, costing $\$ 29,000$ per case compared with $\$ 18,000$ per case in establishments without safety training. Our data suggest that firms may employ safety training in a bid to improve their injury records.

\subsection{Estimating Framework}

Fig. (1) gives an overview of the analysis process. Since $15 \%$ of our sample reports a zero days-away-from-work injury rate, we estimated a two-part model of injury rates. In the first stage, we analyzed a 0-1 (dummy) variable for a report of at least one days-away-from-work injury, with a univariate probit. (A probit regression estimates the probability that a normally distributed variable will have a value of 1 rather than 0 , i.e., the probability that an event occurred). In the second stage, we estimated a log-linear regression for those establishments with injuries using the $\log$ of the days-away-from-work injury rate as the dependent variable. Thus, the model allows the process underlying the reporting of injuries to be different between establishments with no injuries and those with a positive number of daysaway-from-work injuries ${ }^{5}$. [9]

The coefficient on safety training in a simple regression of the injury rate on establishment characteristics may not reflect the causal effect of safety training. Rather, an establishment decision to provide training may be indicative of other observable and unobservable factors which themselves may affect the injury rate. For example, Habeck et al. [10] found that firms with an open managerial style and

\footnotetext{
${ }^{4}$ The overall mean days-away-from-work rate is 1.6 per 100 FTEs, lower than the 2.9 rate reported by the BLS for 1993 [5]. This difference is not surprising since our weights were rescaled to match the industry-size composition of the SEPT93 survey rather than the injury survey.

${ }^{5}$ While the data could also be analyzed using a tobit, the two-part model has the advantage of allowing the covariates to have different effects in the two stages of estimation. Manning et al. [9] used Monte Carlo simulations to show that the two-part model which ignores the correlation between the two stages dominates a model that accounts for the correlation.
} 
Table 1. Safety Training Provided by Firms in the Merged Survey of Employer-Provided Training/Survey of Occupational Injuries and Illnesses Data File*

\begin{tabular}{|c|c|c|c|c|c|c|c|}
\hline & Safety & Apprentice & Basic & Work-Place & Job Skills & Orientation & Injury Rate \\
\hline Original SEPT93 & 0.32 & 0.19 & 0.02 & 0.36 & 0.49 & 0.32 & -- \\
\hline Merged SEPT93-SOII & 0.39 & 0.24 & 0.02 & 0.48 & 0.62 & 0.42 & 1.58 \\
\hline \multicolumn{8}{|l|}{ By Establishment Size } \\
\hline$<=49$ employees & 0.35 & 0.23 & 0.01 & 0.46 & 0.60 & 0.38 & 1.37 \\
\hline 50-49 employees & 0.81 & 0.29 & 0.02 & 0.86 & 0.87 & 0.80 & 4.55 \\
\hline 100-499 employees & 0.80 & 0.38 & 0.11 & 0.84 & 0.88 & 0.87 & 4.03 \\
\hline 500-999 employees & 0.95 & 0.39 & 0.18 & 0.93 & 0.98 & 0.94 & 3.03 \\
\hline$>=1000$ employees & 0.91 & 0.53 & 0.44 & 0.95 & 0.95 & 0.91 & 2.96 \\
\hline \multicolumn{8}{|l|}{ By Major Industry } \\
\hline Agriculture $^{1}$ & 1.00 & 0.66 & 0.00 & 0.99 & 0.99 & 0.67 & 0.14 \\
\hline Mining & 0.56 & 0.03 & 0.18 & 0.40 & 0.55 & 0.20 & 5.42 \\
\hline Construction & 0.64 & 0.32 & 0.00 & 0.42 & 0.47 & 0.37 & 13.36 \\
\hline Manufacturing & 0.56 & 0.10 & 0.14 & 0.47 & 0.57 & 0.45 & 3.64 \\
\hline Transport/Communications/Utilities & 0.61 & 0.44 & 0.11 & 0.69 & 0.70 & 0.47 & 1.13 \\
\hline Wholesale Trade & 0.31 & 0.10 & 0.00 & 0.24 & 0.43 & 0.52 & 1.81 \\
\hline Retail Trade & 0.41 & 0.37 & 0.00 & 0.60 & 0.77 & 0.52 & 0.26 \\
\hline Finance/Insurance/Real Estate & 0.03 & 0.03 & 0.01 & 0.06 & 0.07 & 0.04 & 0.07 \\
\hline Services & 0.17 & 0.02 & 0.00 & 0.52 & 0.58 & 0.41 & 0.23 \\
\hline \multicolumn{8}{|c|}{ Establishment Characteristics by Safety Training } \\
\hline & \multicolumn{3}{|c|}{ No Training Safety $=0$} & \multicolumn{4}{|c|}{ With Training Safety $=1$} \\
\hline$\%$ part-time & \multicolumn{3}{|c|}{$29 \%$} & \multicolumn{4}{|c|}{$13 \%$} \\
\hline$\%$ with tenure less than 1 year & \multicolumn{3}{|c|}{$25 \%$} & \multicolumn{4}{|c|}{$17 \%$} \\
\hline$\%$ covered by collective bargaining & \multicolumn{3}{|c|}{$9 \%$} & \multicolumn{4}{|c|}{$23 \%$} \\
\hline Cost of DAFW cases/FTE & \multicolumn{3}{|c|}{$\$ 86$} & \multicolumn{4}{|c|}{$\$ 555$} \\
\hline Cost/DAFW case & \multicolumn{3}{|c|}{$\$ 18,027$} & \multicolumn{4}{|c|}{$\$ 28,851$} \\
\hline Rate of DAFW cases/100 FTEs & \multicolumn{3}{|c|}{1.24} & \multicolumn{4}{|c|}{2.12} \\
\hline$\%$ with paid leave & \multicolumn{3}{|c|}{$44 \%$} & \multicolumn{4}{|c|}{$78 \%$} \\
\hline$\%$ with health insurance & \multicolumn{3}{|c|}{$30 \%$} & \multicolumn{4}{|c|}{$74 \%$} \\
\hline$\%$ with EAP & \multicolumn{3}{|c|}{$1 \%$} & \multicolumn{4}{|c|}{$13 \%$} \\
\hline$\%$ with wellness program & \multicolumn{3}{|c|}{$.4 \%$} & \multicolumn{4}{|c|}{$4 \%$} \\
\hline$\%$ with just-in-time inventories & \multicolumn{3}{|c|}{$14 \%$} & \multicolumn{4}{|c|}{$15 \%$} \\
\hline$\%$ with worker teams & \multicolumn{3}{|c|}{$6 \%$} & & & $17 \%$ & \\
\hline$\%$ with total quality management & & $18 \%$ & & & & $38 \%$ & \\
\hline$\%$ with quality circles & & $2 \%$ & & & & $6 \%$ & \\
\hline
\end{tabular}

${ }^{1}$ Establishments are in the agricultural services sector.

* DAFW = Days-away-from-work injury and illness. FTE $=$ full-time equivalent employee. All data are weighted to national estimates for the U.S.

a corporate culture with an "obvious human resource orientation" had lower claim rates than average. Failing to control for these other policies can upwardly bias the estimated injury rate reduction resulting from safety training.
Conversely, those firms with hazardous jobs and high rates of injury also may be more inclined to offer training as a remedial practice, resulting in a positive relationship between training and injury rates in a simple regression. 


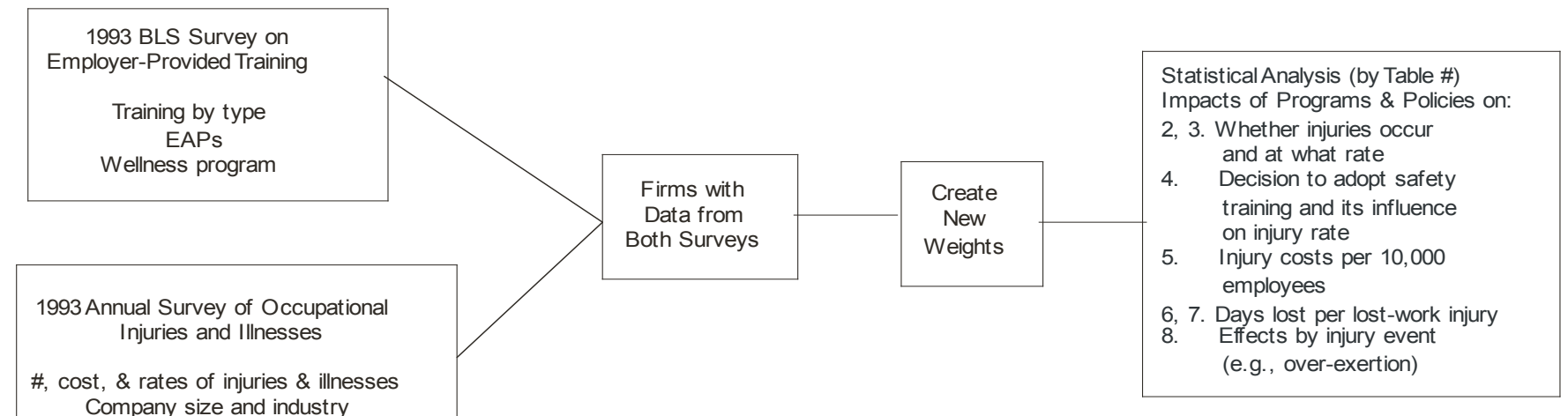

Fig. (1). Overview of the study's methodology.

We used an instrumental variables approach to control for this potential endogeneity of safety training. In this approach, the coefficient on safety training is estimated in two-stages In the first stage we used a univariate probit to predict if the establishment offered safety training. We used the predicted value as an instrument in the second-stage injury equation. Identification of the model depends on locating elements that affect the provision of safety training but are uncorrelated with the injury rate. We used the provision of formal orientation programs to identify the model. This model purged the training coefficient of any unobserved correlation between the process generating injuries and the decision to provide safety training and thus, should provide cleaner [9] estimates of the causal effect of safety training on the rate of days-away-from-work injuries. All analyses were run using STATA software.

We examined the relationship between safety training and the probability of cases in five categories of days away from work (1-3, 4-6, 7-20, 20-60, and greater than 60 days) using grouped ordered logits. Using a log-normal distribution, a grouped ordered logit regression predicts the probability that an observation will fall into different duration categories. We used two-part models to analyze the rate of different underlying injury events (contact, falls, exertion, transportation, exposure, assaults and explosions, and other events) in establishments with and without formal safety training programs. Our results, thus, detail the kinds of days-away-from-work injuries (shorter versus longer duration injuries, or falls versus overexertion) that may be most responsive to safety training programs.

\subsection{Explanatory Factors}

Safety training and the rate of days-away-from-work cases depend on the characteristics of the establishment workforce, the injury record of the industry, and workplace characteristics like innovativeness and generosity of employee benefits.

\subsubsection{Establishment Workforce}

We controlled for establishment size, the percentage of new workers, part-time workers, and workers covered by a union contract in both training and injury equations. Prior research suggests an inverted-U relationship between firm size and injury rates [11], a pattern that is repeated in our data. We merged information on the occupational composition of the 3-digit industry to which the establishment belongs and the earnings of production workers in the industry to further control for variation in injury rates that may be attributed to workforce composition. These data came from the 1992-1994 Occupational Employment Surveys of the BLS. The percentage of workers in seven major occupational groups was calculated at the most detailed industry level possible and then merged with the matched SEPT93-SOII data.

In the injury equation, we included the rate of days-awayfrom-work cases at the three-digit industry level to control for the variation in riskiness of work across establishments. For both injury and training equations, we controlled for whether restricted work was used at all, shifting injured workers from the days-away-from-work category to the restricted-work-only category $[12,13]$. We included twodigit industry dummies where possible to further control for unobserved differences across industries.

\subsubsection{Employee Benefits}

Establishments providing health insurance, sick leave and related benefits may be more attuned to their workers' health and safety concerns. Workers in establishments that provide paid leave for sickness or personal reasons may be less inclined to use the workers' compensation system which requires a waiting period before qualifying for partial income replacement. Finally, EAPs and wellness programs may improve safety by reducing workplace substance use and encouraging a healthful lifestyle. In Washington state, workers' compensation premia are discounted if firms put an injury prevention plan into place that includes EAPs. While a survey of 50 companies credited EAPs with a $17 \%$ reduction in occupational injury, no large-scale research exists on this topic [14]. In the training and injury equations, we controlled separately for different benefits like flexible work schedules, health insurance, paid leave, EAP programs and wellness programs, since we were interested in their individual effects on the injury rate and the provision of safety training.

\subsubsection{Innovative Workplace}

Critics of innovative work practices charge that they have reduced worker autonomy on the shop floor and endangered worker safety and health by speeding up the production process (e.g. Parker [15]). Brenner et al. [16] show that quality circles and just-in-time production in particular, have a sizeable, positive and statistically significant effect on the rate of 
cumulative trauma disorders including carpal tunnel syndrome. We used dummy variables to control for the use of just-in-time inventories and innovative work practices like worker teams, total quality management, quality circles, employee involvement, and job rotation in both the safety and injury equations.

\subsubsection{State OSH Plans, Workers' Compensation}

As of 1993, 20 states had obtained federal approval to operate their own OSH programs rather than remain under the Federal Occupational Safety and Health Administration. According to Finkin et al. [17] state plans employed more compliance officers and undertook more inspections than the federal plan but also imposed lower fines for violations. While the majority of state OSH programs were similar to the federal program, California, Hawaii, Michigan, Oregon, and Washington had different, generally tougher requirements.

In addition to a variable denoting SOHSA jurisdiction, we included the state waiting period to qualify for workers' compensation and the average income replacement rate faced by a firm to control for any incentive effects on the days-awayfrom-work rate.

\subsubsection{Other Formal Training}

Teaching basic language skills or training a worker in production-related skills such as how to operate or repair machinery can have positive safety consequences over and above their immediate effects on worker productivity. Likewise, formal training in workplace practices (equal opportunity, environmental, or collective bargaining provisions; policies on sexual harassment and diversity; how to work in groups; time management, leadership; communication skills) may affect the reported injury rate by informing workers about the remedies available to them in the event of a workplace injury. Four motivations for providing formal job skills training were included to explain both safety training and the injury rate: bargaining contracts, workers lacking in skill or needing special skills, upgrading or introducing new technology, and legal requirements.

In contrast, formal orientation training defined as providing "information on personnel and workplace practices and overall company policies" may be reasonably expected to have no effect on injuries. However, establishments that conduct orientation programs may be more likely to have the training facilities needed to provide formal safety and health training, may have a culture of providing employee training, and may use purchased orientation materials that include safety messages. In our IV models, we restricted formal orientation to affect only the safety training decision and not injury outcomes, helping to identify the injury equation. We tested and confirmed the validity of this restriction.

\subsection{Models Run}

Models were estimated for the full sample and by establishment size (less than or greater than 250 workers). We analyzed four dependent variables - the logged rate of daysaway-from-work injury cases per 10,000 FTEs; the logged total cost of days-away-from-work cases per 10,000 FTEs; the probability of cases in the five duration categories; and for selected injury events. The latter two variables were analyzed using grouped ordered logits and two-part models respectively.
Robust standard errors allowed clustering of observations within 40 industry-size groups.

\section{RESULTS AND DISCUSSION}

\subsection{The Rate of Days-away-from Work Injuries}

Table 2 reports the estimated difference in the mean rate of days-away-from-work injuries for the average establishment in the full sample and by size class using coefficients from the two-part model ${ }^{6}$. Controlling for other characteristics, establishments with safety training have approximately 27 more days-away-from-work cases per 10,000 FTEs than those with no training, a statistically significant difference. Since the mean rate of days-away-from-work cases (per 10,000 FTEs) is 160 for all establishments, this amounts to a $17 \%$ higher rate for establishments with safety training [18].

The result is similar when we consider establishments separately by size - those with safety training have a $13 \%$ and $43 \%$ higher rate of days-away-from-work injuries respectively for the average small and large establishment, and the relationships are statistically significant. Similarly, training correlated with a higher mean days-away-from-work rate for the average establishment in the manufacturing and construction industries (not tabulated).

It seems unreasonable that safety and health training would cause an increase in the injury rate. Instead, these results indicate either a greater incentive for firms with costly days-away-from-work injuries to adopt palliative safety training programs or a greater tendency to report injuries in establishments with formal safety training programs. Brenner et al. [16] noted that workplace innovations had reporting effects on cumulative trauma injury rates. To distinguish between these competing explanations, we examine the coefficients from the two-part model in Table 3.

Formal safety training is positively and significantly associated with a higher probability of a positive number of days-away-from-work injuries but also is associated with a significant $24 \%$ reduction in the injury rate for the subset of establishments with injuries according to column (1) of Table $3^{7}$. The results are similar when we examine small firms separately in column (2). Conversely, safety training significantly reduces the probability of days-away-fromwork injuries in large establishments but is positively and significantly associated with the rate of injury for large establishments with days-away-from-work cases.

\footnotetext{
${ }^{6}$ The marginal effect of a change in the variable of interest on the mean injury rate I is evaluated at the sample mean $\bar{X}$ and calculated as $\frac{d I}{d X_{j}}=\left(\Delta F\left(X \beta_{1}\right)+\beta_{2 j} F\left(X \beta_{1}\right)\right) \cdot \exp \left(X \beta_{2}+\frac{\sigma^{2}}{2}\right)$ where $\mathrm{B}_{1}$ and $\mathrm{B}_{2}$ are the coefficients from the first and second stages of the two-part model and $\mathrm{j}$ indexes the variables. For dummy variables, $\Delta F\left(X \beta_{1}\right)$ is calculated as the discrete change in the standard normal distribution function as the variable changes from 0 to 1 , holding the other variables at their means. For continuous variables, $\Delta F\left(X \beta_{1}\right)$ is calculated as the derivative of the standard normal distribution function with respect to the variable $X_{j}$. Standard errors are calculated using the delta method [18].

${ }^{7}$ The percentage change in injury rates in the second-stage of the two-part model is calculated as $\mathrm{e}^{\beta}-1$.
} 
Table 2. Estimated Marginal Effects of Workplace Policies and Programs on Mean Rate of Days-away-from-Work Injury Cases*

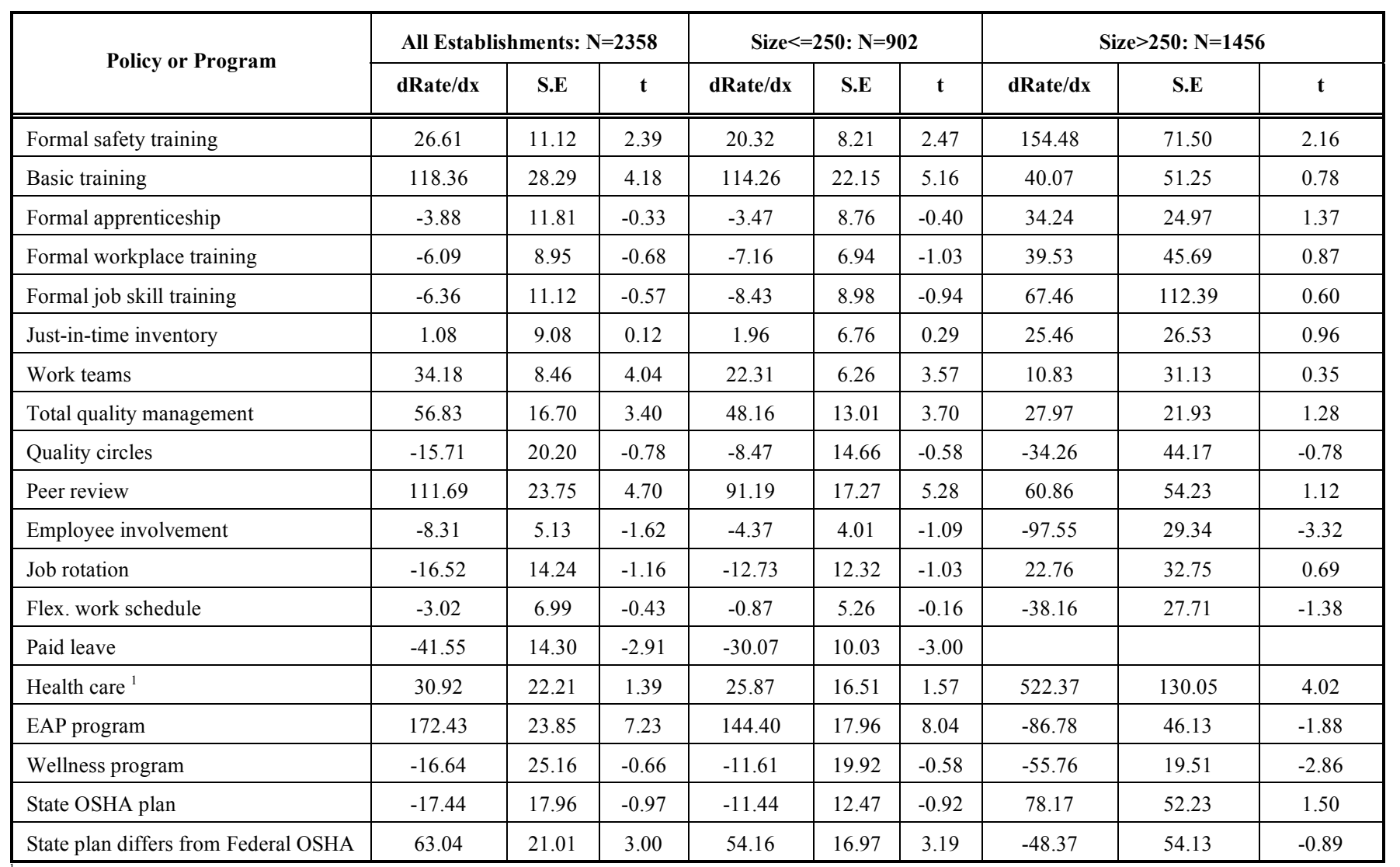

${ }^{\mathrm{I}}$ Healthcare and paid leave are combined in the models for large firms.

* Marginal effects evaluated at the average X using two-part coefficients; standard errors calculated using the delta method. The mean number of days-away cases per 10,000 FTEs is 160 for the full sample, 156 in small firms with 250 employees or less and 357 in large firms with more than 250 employees. dRate/dx $=$ the change in injury rate when the policy or program exists at the firm. S.E. = standard error. All programs and policies are coded as 1 if present, 0 if not present. Based on weighted data.

Underreporting of days-away-from-work injuries may be a bigger problem for those firms reporting no cases at all than among those firms already reporting a positive number. If safety training increases the reporting of injuries, this effect would be stronger in the first stage of the two-part model rather than the second stage. This occurs in our model for both the full sample and for small establishments - safety training is positively related to the probability of a non-zero number of days-away-from-work cases while reducing the days-away-from-work injury rate for those establishments already reporting cases ${ }^{8}$.

These results suggest that the increase in the mean rate of days-away-from-work cases for establishments with safety training is consistent with a reporting effect especially in smaller establishments. However, these reporting effects are not present for large establishments whose safety training appears to be a response to a poor injury record. It is also possible that small firms that have formal safety training programs are generally more careful in other unobservable ways resulting in a lower injury rate. We next examine this potential endogeneity of safety training.

\subsection{Endogenous Safety Training}

Table 4 reports instrumental variable (IV) estimates purged of any unobserved correlation between safety training and the days-away-from-work injury rate. The data are restricted to

\footnotetext{
${ }^{8}$ Two-part coefficients by industry reveal a similar story.
}

establishments reporting a positive days-away-from-work injury rate.

The estimated safety effects are slightly larger than the twopart coefficients for the full sample and for smaller establishments. We tested for the exogeneity of safety training using an augmented regression [19]. We cannot reject the hypothesis that safety training is exogenous in the models for the full sample and for the smaller size category $(\mathrm{p}=0.72$, and 0.98 respectively). The wide range of establishment variables that are available in our data appear to help control for underlying characteristics that influence both the provision of training and the injury rate ${ }^{9}$. On the other hand, for large establishments, the IV model suggests that there are no real training effects and we should treat safety training as endogenous ( $\mathrm{p}=0.16)$. The IV results for large firms indicate an upward bias in the two-part coefficient on safety training.

The results support our conjecture that the estimated higher mean injury rate reported in Table $\mathbf{2}$ for small firms with formal safety training is due more to a positive reporting effect of safety training than due to any remedial safety actions by

\footnotetext{
${ }^{9}$ The exogeneity test for safety training yielded a much smaller p-value of 0.21 for a sparse model that excluded other training, workplace innovation, and benefit. A sparse IV model of logged days-away-from-work injury rates implied a $42 \%$ lower reported injury rate due to safety training.
} 
Table 3. Two-Part Regression Model Predicting If Injuries Involving Days-Away-from-Work Occurred and Rate of Days-awayfrom-Work Injury Cases for Establishments with Cases*

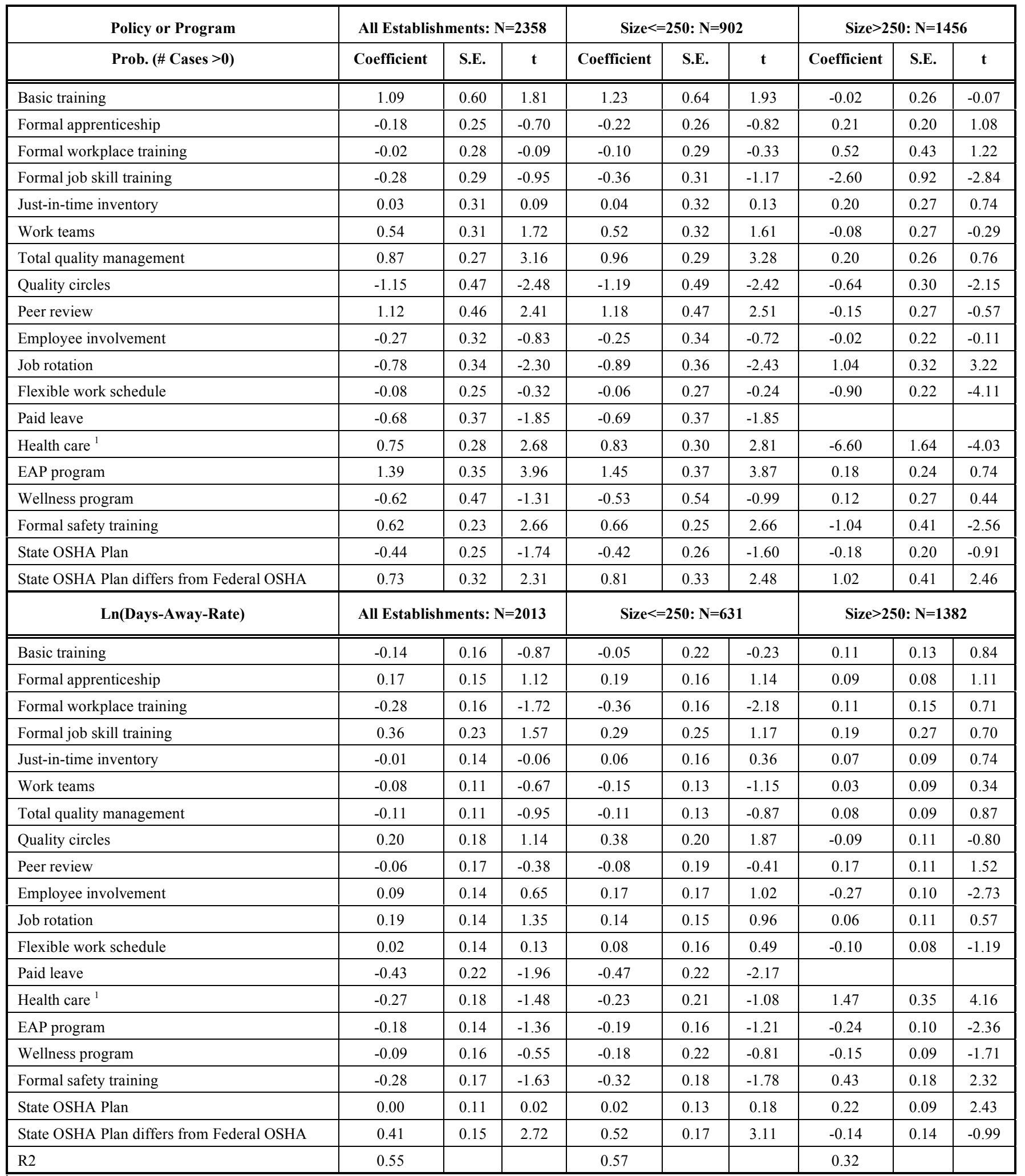

${ }^{1}$ Healthcare and paid leave are combined in the models for large firms.

* Robust standard errors allow for correlation within industry-size groups. Other controls include percentage of employees (a) at the firm for less than one year, (b) part-time and (c) in unions; reasons for job skills training; whether establishment had restricted work cases; establishment size categories; 2-digit Standard Industrial Code dummies; occupational and gender composition of the industry, state waiting period to qualify for Workers' Compensation disability pay; average Workers' Compensation income replacement rate in the State; and log average annual earnings for production workers in the establishment's industry. S.E. = standard error. All programs and policies are coded as 1 if present, 0 if not present. Based on weighted data. 
Table 4. Two-Part Model Predicting If the Establishment Offered Safety Training and the Log Rate of Days-Away-from-Work Injuries with Endogenous Safety Training (2SLS)*

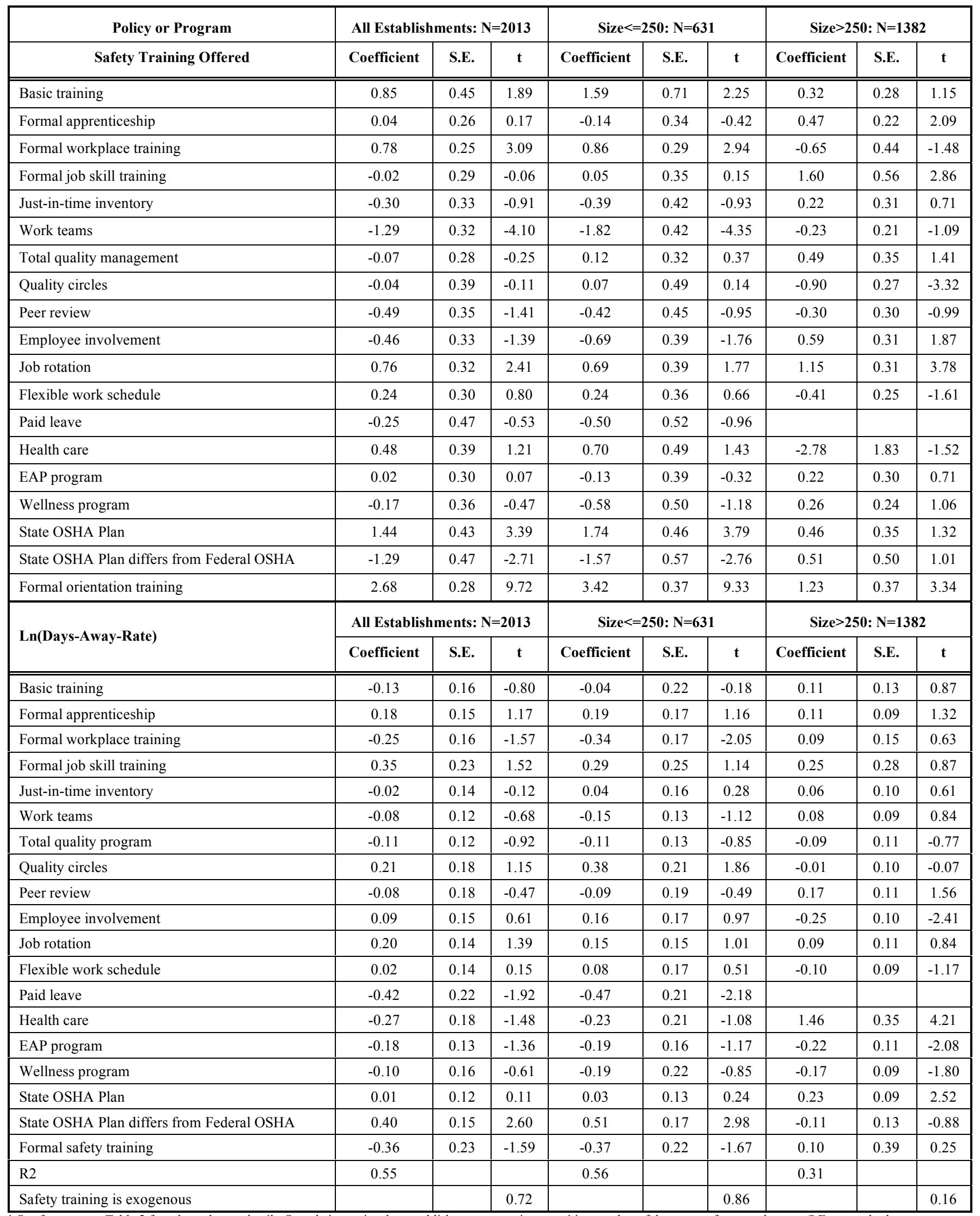

\footnotetext{
* See footnotes to Table $\mathbf{3}$ for other relevant details. Sample is restricted to establishments reporting a positive number of days-away-from-work cases. S.E. $=$ standard error.
} 
Table 5. Regression Model Predicting Logged Cost of Days-away-from-Work Injuries per 10,000 Full-Time-Equivalent Employees*

\begin{tabular}{|c|c|c|c|c|c|c|c|c|c|}
\hline \multirow{3}{*}{ Policy or Program } & \multicolumn{3}{|c|}{ All Establishments } & \multicolumn{3}{|c|}{ Small Establishments } & \multicolumn{3}{|c|}{ Large Establishments } \\
\hline & \multicolumn{3}{|c|}{$\mathrm{N}=1921$} & \multicolumn{3}{|c|}{$N=594$} & \multicolumn{3}{|c|}{$N=1327$} \\
\hline & Coefficient & S.E & $\mathbf{t}$ & Coefficient & S.E & $\mathbf{t}$ & Coefficient & S.E & $\mathbf{t}$ \\
\hline Basic training & -0.02 & 0.21 & -0.08 & 0.03 & 0.30 & 0.11 & 0.00 & 0.10 & 0.02 \\
\hline Formal apprenticeship & 0.40 & 0.18 & 2.24 & 0.47 & 0.22 & 2.15 & 0.05 & 0.09 & 0.50 \\
\hline Formal workplace training & -0.08 & 0.27 & -0.29 & -0.05 & 0.29 & -0.18 & 0.26 & 0.15 & 1.72 \\
\hline Formal job skill training & 0.13 & 0.35 & 0.37 & 0.16 & 0.39 & 0.40 & 0.42 & 0.26 & 1.59 \\
\hline Just-in-time inventory & 0.29 & 0.19 & 1.51 & 0.33 & 0.24 & 1.39 & 0.04 & 0.10 & 0.37 \\
\hline Work teams & -0.02 & 0.18 & -0.11 & -0.03 & 0.23 & -0.11 & 0.07 & 0.09 & 0.74 \\
\hline Total quality management & -0.11 & 0.16 & -0.71 & -0.17 & 0.19 & -0.92 & 0.03 & 0.09 & 0.36 \\
\hline Quality circles & 0.46 & 0.23 & 1.98 & 0.70 & 0.30 & 2.32 & 0.01 & 0.11 & 0.05 \\
\hline Peer review & -0.14 & 0.21 & -0.67 & -0.14 & 0.24 & -0.57 & -0.07 & 0.13 & -0.54 \\
\hline Employee involvement & 0.02 & 0.18 & 0.10 & 0.01 & 0.22 & 0.04 & -0.18 & 0.10 & -1.78 \\
\hline Job rotation & 0.42 & 0.21 & 1.96 & 0.47 & 0.26 & 1.80 & 0.06 & 0.11 & 0.54 \\
\hline Flexible work schedule & -0.21 & 0.19 & -1.07 & -0.18 & 0.24 & -0.79 & -0.11 & 0.09 & -1.25 \\
\hline Paid leave & -0.45 & 0.38 & -1.19 & -0.50 & 0.41 & -1.21 & & & \\
\hline Health care & -0.31 & 0.35 & -0.88 & -0.29 & 0.44 & -0.66 & 0.30 & 0.32 & 0.92 \\
\hline EAP program & 0.23 & 0.14 & 1.62 & 0.25 & 0.17 & 1.50 & -0.20 & 0.11 & -1.79 \\
\hline Wellness program & -0.42 & 0.18 & -2.27 & -0.64 & 0.27 & -2.40 & -0.12 & 0.09 & -1.26 \\
\hline State OSHA Plan & -0.23 & 0.18 & -1.29 & -0.31 & 0.22 & -1.37 & 0.10 & 0.09 & 1.03 \\
\hline State OSHA Plan differs from Federal OSHA & 0.67 & 0.24 & 2.81 & 0.75 & 0.29 & 2.61 & 0.03 & 0.13 & 0.26 \\
\hline Formal safety training & -0.05 & 0.23 & -0.21 & -0.02 & 0.26 & -0.09 & 0.52 & 0.16 & 3.35 \\
\hline $\mathrm{R} 2$ & 0.43 & & & 0.45 & & & 0.35 & & \\
\hline
\end{tabular}

* See footnotes to Table 3 for other relevant details. Sample is restricted to establishments reporting a positive number of days-away-from-work cases and with cost information. S.E. $=$ standard error.

establishments with poorer injury records. In fact, to the extent that small firms take remedial actions, our coefficient on formal safety training would conservative estimately training effects on days-away-from-work cases. The reporting effects of safety training are not unexpected given that many safety programs also have a strong reporting component to facilitate treatment for injuries. For example, an intervention to prevent needle stick injuries also encouraged reporting and follow-up laboratory work to test for HIV [20].

Table 4 also provides information about those establishment characteristics that are consistent with a formal safety training program. Worker teams were negatively associated with formal safety programs while job rotation was positively related. Total quality management was insignificantly related to safety training.

State-run safety and health plans increased the probability of safety training in small firms but in states where the OSH program differed from the federal program, the probability of formal safety and health training was lower. For large firms, state OSH plans had positive but statistically insignificant effects on safety and health training.
The provision of orientation training was a strong predictor of a formal safety training program. Establishments offering other types of formal training like basic skills training, or workplace training were also significantly more likely to provide formal safety training. Controlling for other training, benefit provisions were generally unrelated to safety training. The existence of an EAP program did not significantly alter the provision of safety and health training.

Finally, among results not reported in the tables, a longer state waiting period decreases the probability of safety training in small firms suggesting that safety training may be a response to compensation costs. The average replacement rate facing the firm is negatively related to safety training, possibly reflecting workforce composition ${ }^{10}$. The average industry days-away-from-work injury rate strongly increases (decreases) the probability of safety training in large (small) firms. Controlling for riskiness of work, workers' compensation variables have no significant effect on training in large firms.

\footnotetext{
${ }^{10}$ Since weekly income replacement is capped, low wage workers have higher replacement rates but may also be less likely to receive formal training.
} 
Table 6. Grouped Ordered Logit Model Predicting Days-away-from-Work Injuries by Duration*

\begin{tabular}{|c|c|c|c|c|c|c|c|c|c|}
\hline Policy or Program & Coefficient & S.E & $\mathbf{z}$ & Coefficient & S.E & $\mathbf{z}$ & Coefficient & S.E & $\mathbf{z}$ \\
\hline Formal safety training & -0.40 & 0.04 & -9.71 & 0.08 & 0.07 & 1.27 & -0.81 & 0.06 & -13.67 \\
\hline Basic training & 0.06 & 0.02 & 3.89 & 0.22 & 0.10 & 2.23 & 0.07 & 0.02 & 4.26 \\
\hline Formal workplace training & 0.34 & 0.03 & 10.27 & 0.14 & 0.07 & 2.10 & 0.45 & 0.04 & 11.14 \\
\hline Formal job skill training & -0.35 & 0.04 & -8.65 & -0.68 & 0.08 & -8.39 & -0.10 & 0.05 & -1.99 \\
\hline Just-in-time inventory & -0.13 & 0.02 & -7.04 & 0.17 & 0.07 & 2.57 & -0.12 & 0.02 & -6.21 \\
\hline Work teams & 0.02 & 0.02 & 0.85 & 0.09 & 0.06 & 1.41 & 0.05 & 0.02 & 2.32 \\
\hline Employee involvement & 0.05 & 0.02 & 2.91 & -0.15 & 0.08 & -2.04 & 0.06 & 0.02 & 3.09 \\
\hline Job rotation & -0.07 & 0.02 & -3.77 & -0.03 & 0.07 & -0.41 & -0.09 & 0.02 & -4.96 \\
\hline Flexible work schedule & 0.04 & 0.02 & 2.29 & -0.01 & 0.06 & -0.14 & 0.04 & 0.02 & 2.06 \\
\hline Paid leave & -0.15 & 0.07 & -2.10 & 0.04 & 0.11 & 0.39 & & & \\
\hline Health care & 0.23 & 0.06 & 4.02 & -0.14 & 0.10 & -1.48 & -1.00 & 0.30 & -3.31 \\
\hline EAP program & 0.04 & 0.02 & 2.03 & 0.27 & 0.06 & 4.52 & -0.05 & 0.02 & -2.08 \\
\hline Wellness program & 0.13 & 0.02 & 7.66 & -0.24 & 0.08 & -3.00 & 0.16 & 0.02 & 9.30 \\
\hline State OSHA Plan & -0.26 & 0.02 & $\begin{array}{c}- \\
14.93 \\
\end{array}$ & -0.36 & 0.06 & -6.31 & -0.25 & 0.02 & -13.66 \\
\hline
\end{tabular}

* See footnotes to Table 3 for other relevant details. Sample is restricted to establishments reporting a positive number of days-away cases with non-missing data for the counts in different severity categories. Five duration categories are modeled $-1-3$ days, $4-6$ days, $7-20$ days, $21-60$ days, and $>=60$ days. S.E. $=$ standard error.

\subsection{Cost of Injuries}

To assess the injury cost differential associated with safety training programs, we report coefficients from simple regression models of logged total costs of days-away-fromwork injuries per 10,000 FTEs in Table 5. Safety training is associated with a statistically insignificant reduction in total days-away-from-work injury costs per employee, both for the full sample $(-5 \%)$ and for smaller establishments. For larger establishments with more than 500 employees, safety training is associated with a significant $68 \%$ increase in the costs per employee suggesting again that establishments with a greater number and severity of injuries tend to adopt such programs ${ }^{11}$.

\subsection{Severity of Injuries}

To further analyze safety effects on the severity of injuries we modeled the distribution of injury durations using grouped ordered logits (Table 6). The results show that for the full sample and larger establishments, a formal safety training program increases (reduces) the likelihood of the least (most) severe injuries with between 1 and 3 (over 60) days away from work. The increased reporting of days- away-from-work cases in small establishments should especially affect short-duration cases that may otherwise have gone unreported in the absence of formal training. However, the opposite result holds with training positively related to severity in small firms though the coefficient is statistically insignificant.

A more straightforward look at the effect of safety training on the probability of injuries of different durations can be seen from Table 7 where we predict the probability of each severity category with and without safety training, holding all other variables constant. For larger establishments, formal safety training is associated with a significantly increased probability of shorter duration injuries with fewer than six days away from work and a significantly reduced probability of injuries with seven or more days away from work. The results for small firms are reversed and safety training does not seem to have a significant relationship with injury severity.

\subsection{Injury Events}

We examined the responsiveness of different injury events to safety training using two-part models of the event rate per 10,000 FTEs (Table 8). Establishments with safety

\footnotetext{
${ }^{11}$ We also estimated IV models with qualitatively similar results.
} 
Table 7. Predicted Distribution of Days-Away-from-Work Injuries by Safety Training*

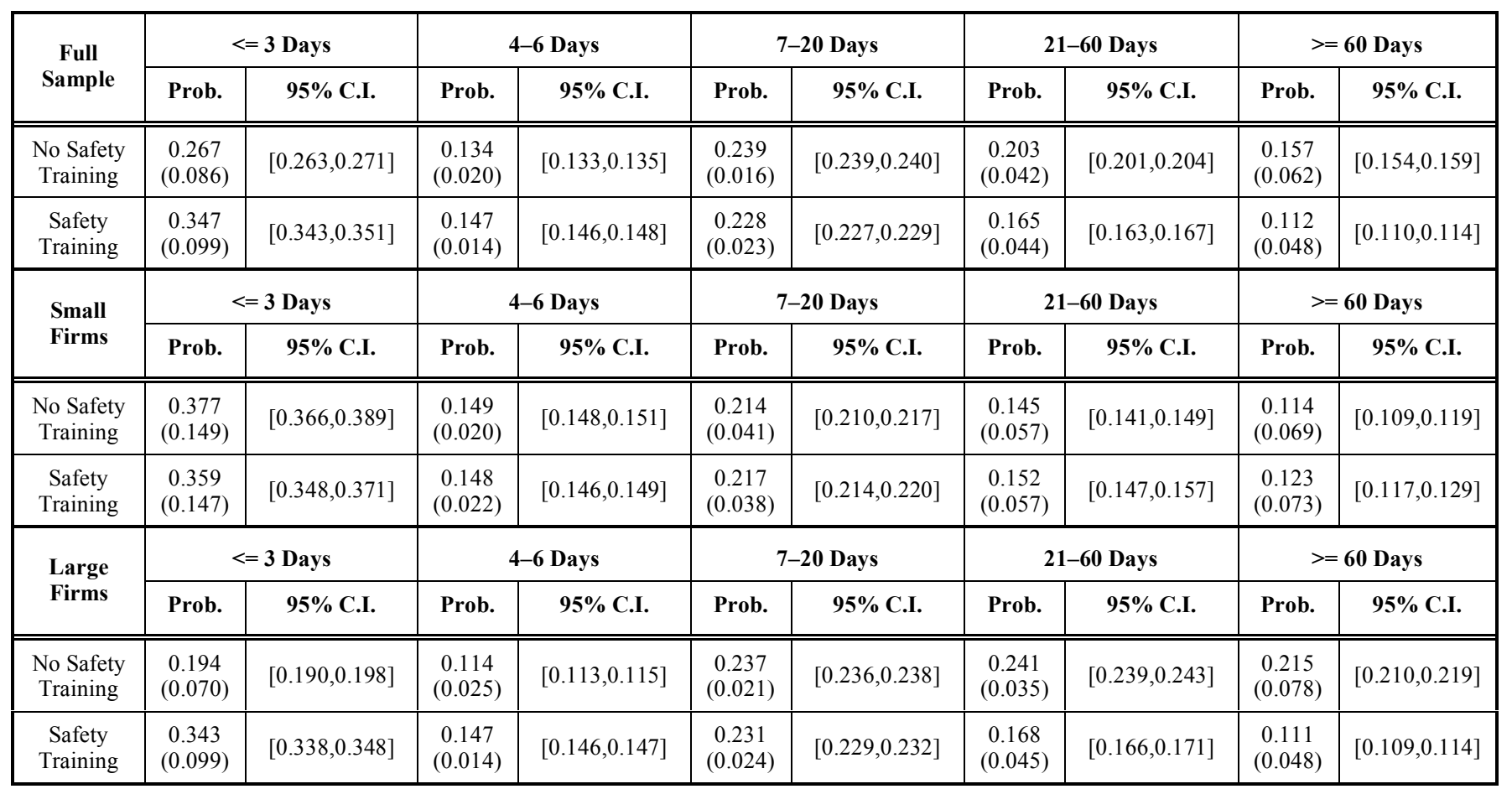

* Standard deviations of the probabilities are in parentheses. C.I. = confidence interval. Based on weighted data.

training have a significantly lower rate of contact injuries and falls where these occur ${ }^{12}$. However, safety training is associated with a higher probability of overexertion injuries. The resistance of overexertion injuries to safety training is not surprising given the complexity of back disorders. As Carlton [21] shows, even when workers are trained in proper ergonomic techniques, these may not be readily implemented due to other considerations like the worksite layout.

Workers in different industries are not equally exposed to different injury events - for example, the majority of injuries resulting from toxic exposure to chemicals occur in manufacturing. We re-examined the distribution of injury events after restricting the data to manufacturing establishments. Manufacturing establishments with safety training have a significantly lower rate of injuries resulting from toxic exposure, a gratifying result since such incidents are the explicit target of many OSHA training requirements.

\subsection{Other Results}

Table 2 presents the relationship between other characteristics and the mean days-away-from-work rate in the average establishment. Training in basic skills like English and mathematics was associated with an increase in the mean injury rate. The coefficients in Table $\mathbf{3}$ suggest that this increase was primarily due to improved reporting of days-away-from-work cases. Other types of training were not significantly associated with improved safety in the average establishment ${ }^{13}$.

\footnotetext{
12 Contact injuries include being struck or compressed by objects or equipment or being crushed in collapsing materials (e.g. trench cave-in).

${ }^{13}$ These results were relatively unchanged in models where the different training variables were entered one at a time. We also interacted job skills and safety training. The interaction variable had a negative effect on the
}

Workplace innovations like total quality management, worker teams and peer review were associated with large and statistically significant increases in the mean rates for the full sample and smaller establishments, primarily reporting effects. Brenner et al. [16] found just-in-time-delivery and quality circles were positively and significantly associated with the rate of carpal tunnel disorders. However, these innovations have insignificant effects on the days-awayfrom-work injury rate in our models. Controlling for other innovative practices, quality circles and in some cases, job rotation were associated with a significantly lower reporting of days-away-from-work injuries.

Employee benefits like health insurance increased the reporting of days-away-from-work cases in small firms. Similarly, EAP programs were associated with 144 more cases per 10,000 FTEs in the minority of small establishments that provided them, primarily a reporting phenomenon. The results were reversed for large firms where EAPs are more prevalent. EAPs are associated with 87 fewer days-away-from-work cases per 10,000 FTEs in the average large establishment (significant at the 99\% confidence level). and with a $20 \%$ lower cost-per-worker of days-away-from-work cases (significant at the $90 \%$ confidence level). Since EAPs intervene in substance abuse and substance abuse causes injury [22], the observed effect on workplace injury probably is causational. Wellness programs were associated with a lower injury rate in large firms where they are more common and with significantly lower injury costs per worker in all firms.

days-away-from-work injury rate in the two-part model suggesting that the two types of training complemented each other - however, the coefficient was statistically insignificant. 
Table 8. Effect of Safety Training on the Occurrence and Rate of Days-away-from-Work Injury by Event*

\begin{tabular}{|c|c|c|c|}
\hline Event & Coefficient & S.E. & $\mathbf{t}$ \\
\hline \multicolumn{4}{|l|}{ Contact Injury } \\
\hline Change in Prob(Inj. $>0)$ & -0.085 & 0.099 & 0.86 \\
\hline $\log ($ Rate $)$ & -0.548 & 0.263 & 2.09 \\
\hline \multicolumn{4}{|l|}{ Fall } \\
\hline Change in Prob(Inj. $>0)$ & -0.059 & 0.075 & 0.82 \\
\hline $\log ($ Rate $)$ & -0.694 & 0.312 & 2.22 \\
\hline \multicolumn{4}{|l|}{ Over-Exertion } \\
\hline Change in Prob(Inj. $>0)$ & 0.252 & 0.102 & 2.57 \\
\hline $\log ($ Rate $)$ & 0.205 & 0.301 & 0.68 \\
\hline \multicolumn{4}{|l|}{ Transportation Injury } \\
\hline Change in Prob(Inj. $>0)$ & 0.019 & 0.008 & 1.57 \\
\hline Log(Rate) & -0.664 & 0.414 & 1.61 \\
\hline \multicolumn{4}{|l|}{ Toxic Exposure } \\
\hline Change in Prob(Inj. $>0$ ) & 0.034 & 0.014 & 1.99 \\
\hline $\log ($ Rate $)$ & -0.465 & 0.484 & 0.96 \\
\hline \multicolumn{4}{|c|}{ Exposure - Manufacturing } \\
\hline Change in Prob(Inj. $>0$ ) & 0.006 & 0.003 & 2.60 \\
\hline Log(Rate) & -1.208 & 0.465 & 2.60 \\
\hline \multicolumn{4}{|c|}{$\begin{array}{l}\text { The average number of day-away-from-work cases per } 10,000 \mathrm{FTEs} \text { in establishment } \\
\text { with a positive number of days-away-from-work cases is } 1,069 \text { for contact injuries } \\
1,174 \text { for falls; } 3,285 \text { for over-exertion; } 84 \text { for exposure; } 161 \text { for transportation; } 50 \text { fo } \\
\text { exposure injuries in manufacturing. See footnote to Table } 3 \text { for other relevant details } \\
\text { Sample is restricted to establishments reporting a positive number of days-away-from } \\
\text { work cases. S.E. = standard error. }\end{array}$} \\
\hline
\end{tabular}

State OSHA plans that were different (i.e. stricter) than federal OSHA plans were positively and significantly related to the mean injury rate for small firms. Table $\mathbf{3}$ shows that for small firms facing these stricter plans, both reporting of some days-away-from-work injuries and the injury rate for establishments with injury cases were higher. These results are consistent with stricter enforcement leading to more complete reporting of injuries. Like the findings about reporting rising with basic skills training and with workplace innovations, they support claims that days-away-from-work injuries are under-reported to BLS and OSHA [23].

\section{CONCLUSION}

This study offers a rare look at the effect of training, benefit packages, and workplace practices on work injury. Our results suggest that safety training increases the reporting of injuries but also has real safety effects on daysaway-from-work injuries, especially in smaller firms. Safety training appears to be more effective in preventing severe injuries in large firms than in small ones. While overexertion injuries were resistant to safety training, toxic exposure events were reduced in manufacturing establishments with a formal safety training program.
By combining data with detailed information on training and other establishment characteristics with data on injury, we were able to control more fully for any underlying correlation between the training decision and an establishment's injury record. Our data on work organization helps to more fully characterize the post-training environment that affects the ease with which training lessons are implemented in the regular workday.

The strengths of this analysis are the large data set, the broad range of relevant variables available, and techniques used to confirm that the correlations observed probably had causative underpinnings and that the findings were robust. The weaknesses are the correlational nature of a crosssectional evaluation, the age of the data, and the lack of detail available about the safety training programs themselves. The findings also may not apply outside the U.S. regulatory environment

Wellness programs and EAPs were associated with lower injury rates in large firms where they are more common. Some evidence suggested that workplace innovations like total quality management significantly increased the reporting of injuries. This study found that quality circles, previously implicated in poor injury outcomes [16], depressed the reporting of injuries.

This study does not refer to specific OSHA safety training requirements. The safety training variable includes a range of activities from general safety admonitions to more specific workplace instructions. Also, we cannot tell how many workers received formal safety training or whether the training was concentrated among workers in hazardous occupations. Still, our results point to some real safety training effects on days-away-from-work cases.

\section{ACKNOWLEDGEMENTS}

This research was supported by grant R01 OH03750 from the National Institute for Occupational Safety and Health of the Centers for Disease Control and Prevention and a contract from the Office of Workplace Programs, Center for Substance Abuse Prevention (CSAP). It was conducted with restricted access BLS data on-site at the BLS. Our thanks to the many BLS staff who assisted us in accessing and merging the data and to Denorah GAlvin, PhD. at CSAP for her insightful comments. The analyses and their interpretation reflect the views of the authors alone and not necessarily of any Federal agency or employee.

\section{ABBREVIATIONS}

\begin{tabular}{|c|c|c|}
\hline BLS & $=$ & U.S. Bureau of Labor Statistics \\
\hline EAPs & $=$ & Employee assistance programs \\
\hline $\mathrm{OSH}$ & $=$ & Occupational safety and health \\
\hline OSHA & $=$ & $\begin{array}{l}\text { U.S. Occupational Safety and Health } \\
\text { Administration }\end{array}$ \\
\hline SEPT93 & $=$ & $\begin{array}{l}1993 \text { BLS survey on employee-provided } \\
\text { training }\end{array}$ \\
\hline SOII & $=$ & $\begin{array}{l}1993 \text { annual survey of occupational injuries } \\
\text { and illnesses }\end{array}$ \\
\hline FTEs & $=$ & Full time equivalents \\
\hline
\end{tabular}




\section{REFERENCES}

[1] Cohen A, Colligan M. Assessing occupational safety and health training: a literature review. Washington, DC: Department of Health and Human Services, Centers for Disease Control and Prevention, National Institute for Occupational Safety and Health; 1998. Report No.: DHHS 98-145.

[2] Frazis H, Gittleman M, Horrigan M, Joyce M. Results from the 1995 Survey of Employer-Provided Training. Mon Labor Rev Online 1998; 121(6): 3-13.

[3] Burke MJ, Sarpy SA, Smith-Crowe K, Chan-Serafin S, Salvador RO, Islam G. Relative effectiveness of worker safety and health training methods. Am J Public Health 2006; 96(2): 315-24.

[4] Frazis H, Herz D, Horrigan M. Employer-provided training: results from a new survey. Mon Labor Rev 1995; 118: 3-17.

[5] Bureau of Labor Statistics. Occupational Injuries and Illnesses Counts, Rates, and Characteristics, 1993. Washington, DC: US Department of Labor, Bureau of Labor Statistics; 1996.

[6] Leigh JP, Waehrer GM, Miller TR, Keenan C. Costs of occupational injury and illness across industries. Scan J Work Environ Health 2004; 30(3): 199-205.

[7] Gittleman M, Horrigan M, Joyce M. 'Flexible' workplace practices: evidence from a nationally representative survey. Ind Labor Relat Rev 1998; 52(1): 99-115.

[8] Hunt A, Habeck R. The michigan disability prevention study research highlights. Kalamazoo, WI: Upjohn Institute for Employment Research; 1993. Report No.: Staff Working Paper 9318.

[9] Manning WG, Duan N, Rogers WH. Monte Carlo evidence on the choice between sample selection and two-part models. J Econom 1987; 45(1): 59-82.

[10] Habeck R, Leahy MJ, Hunt HA. Disability Prevention and Management and Workers' Compensation Claims (Report submitted to Bureau of Workers' Disability Compensation, Michigan Department of Labor). Kalamazoo, MI: W.E. Upjohn Institute for Employment Research 1988.
[11] Ruser JW. Workers' compensation insurance, experience rating, and occupational injuries. Rand J Econ 1985; 16(4): 487-503.

[12] Ruser J. The changing composition of lost-workday injuries. Mon Labor Rev 1999; 122(6): 11-7.

[13] Waehrer GM, Miller TR. Restricted work, worker's compensation and days away from work. J Hum Res 2003; 38(4): 964-91.

[14] Blum TC, Roman PM. Cost-effectiveness and preventive implications of employee assistance programs. Rockville, MD: Substance Abuse and Mental Health Services Administration, Center for Substance Abuse Prevention (CSAP) 1995; Report No.: RP0907 DHHS Publ. No. (SMA)95-3053.

[15] Parker M. Inside the circle: a union guide to QWL. Detroit, MI: Labor Notes/South End Press 1985.

[16] Brenner M, Fairris D, Ruser J. "Flexible" work practices and occupational safety and health: exploring the relationship between cumulative trauma disorders and workplace transformation. Ind Relat 2004; 43(1): 242-66.

[17] Finkin M, Goldman A, Summers C, Dau-Schmidt K. Legal protection for the individual employee. $3^{\text {rd }}$ ed. NY: West Group 2002.

[18] Goldberger A. A Course in econometrics. Cambridge, MA Harvard University Press 1991.

[19] Davidson R, MacKinnon J. Estimation and enference in econometric. NY: Oxford University Press 1993.

[20] Linnemann CC, Cannon C, De Ronde M, Lamphear B. Effect of educational programs, rigid sharp containers and universal precautions on reported needle stick injuries in health care workers. Infect Control Hosp Epidemiol 1991; 12: 214-9.

[21] Carlton RS. The effects of body mechanic instruction on work performance. Am J Occup Ther 1987; 41: 16-20.

[22] Borges G, Cherpitel CJ, Orozco R, et al. Acute alcohol use and the risk of non-fatal injury in sixteen countries. Addiction 2006; 101(7): 993-1002.

[23] Leigh JP, Marcin JP, Miller TR. An estimate of the U.S. government's undercount of non-fatal occupational injuries. J Occup Environ Med 2004; 46(1): 10-8.

(C) Waehrer and Miller; Licensee Bentham Open.

This is an open access article licensed under the terms of the Creative Commons Attribution Non-Commercial License (http: //creativecommons.org/licenses/ by-nc/3.0/) which permits unrestricted, non-commercial use, distribution and reproduction in any medium, provided the work is properly cited. 